\title{
Admission deep venous thrombosis of lower extremity after intertrochanteric fracture in the elderly: a retrospective cohort study
}

Jinzeng $\mathrm{Zuo}^{1,2}$ and Yongcheng $\mathrm{Hu}^{3^{*}}$

\begin{abstract}
Objective: The purpose of this study was to investigate the incidence, location, and related factors of deep venous thrombosis (DVT) of the bilateral lower extremities after intertrochanteric fractures in the elderly.

Methods: Retrospective analysis was performed on the elderly patients with intertrochanteric fracture who were admitted from January 2017 to December 2019. At admission, patients receive routine ultrasound Doppler scanning of bilateral lower extremities to detect DVT; those with DVT were assigned to the case group and those without DVT to the control group. Patient data on demographics, comorbidities, injury-related data, and laboratory test results at admission were extracted. Logistic regression analyses were conducted to identify the independent risk factors associated with DVT.

Results: Five hundred seventy-eight patients were included, among whom 116 (20.1\%) had DVT. Among those with DV, $70.7 \%$ (82/116) had DVT of the distal type, 24 (29.6\%) had DVT of the proximal type, and 10 (10.4\%) had mixed DVT. In $76.7 \%$ (89/116) of patients, DVT occurred in the fractured extremity, $9.5 \%(11 / 116)$ in the bilateral and $13.8 \%(16 / 116)$ in the non-fractured extremity. Multivariate analyses identified obesity, delay to admission, increased D-dimer level (> 1.44 $\mathrm{mg} / \mathrm{L})$ and reduced albumin $(<31.7 \mathrm{~g} / \mathrm{L})$ as independent factors.

Conclusions: Admission incidence of DVT was high in elderly patients with intertrochanteric fractures, especially the proximal DVT. Identification of associated risk factors is useful for individualized assessment risk of DVT and early targeted interventions.
\end{abstract}

Keywords: Hip fracture, Deep vein thrombosis, Epidemiology, Risk factors, Individualized risk assessment

\section{Introduction}

Intertrochanteric fracture is one of the most common fractures in the elderly, constituting 10 20\% of all fractures and $50-65 \%$ of hip fractures [1, 2]. Intertrochanteric fractures are typical osteoporotic fractures and are most commonly caused by low-energy fall injury, with a 1 -month mortality of $5-10 \%$ and 1 -year mortality rate of

\footnotetext{
* Correspondence: yongchenghu@126.com

${ }^{3}$ Department of Orthopaedic Oncology, Tianjin Hospital, Tianjin 300211, P. R. China

Full list of author information is available at the end of the article
}

8-31\% [3]. After an intertrochanteric fracture occurs, the hypercoagulability of blood, post-trauma stress/inflammatory immune response of the body place the patients at a high risk of DVT. It was reported that intertrochanteric fracture itself was a risk factor for DVT, increasing 2.5-fold risk compared to femoral neck fracture [4]. In addition, the high prevalence of multiple comorbidities made elderly patients more susceptible to DVTs than younger patients [5]. Pulmonary embolism $(\mathrm{PE})$ is the third leading cause of death within 24 hours after trauma, and DVT is a most predominant source of

(c) The Author(s). 2020 Open Access This article is licensed under a Creative Commons Attribution 4.0 International License, which permits use, sharing, adaptation, distribution and reproduction in any medium or format, as long as you give appropriate credit to the original author(s) and the source, provide a link to the Creative Commons licence, and indicate if changes were made. The images or other third party material in this article are included in the article's Creative Commons licence, unless indicated otherwise in a credit line to the material. If material is not included in the article's Creative Commons licence and your intended use is not permitted by statutory regulation or exceeds the permitted use, you will need to obtain permission directly from the copyright holder. To view a copy of this licence, visit http://creativecommons.org/licenses/by/4.0/. The Creative Commons Public Domain Dedication waiver (http://creativecommons.org/publicdomain/zero/1.0/) applies to the data made available in this article, unless otherwise stated in a credit line to the data. 
PE [6]. Therefore, prompt detect of DVT and targeted anti-thrombotic therapy are of great significance in preventing progress of DVT proximal to PE.

Plasma D-dimer level is the product of plasminozyme mediated degradation of cross-linked fibrin, having a high sensitivity (more than 95\%) in diagnosing DVT, but is limited in use due to a poor specificity (only 20-40\%) [7]. Despite multiple studies have been performed to identify the risk factors associated with DVT after hip fracture, but most of them were limited by the relatively small sample size or focused on preoperative and postoperative DVTs [8-10], overlooking the clinical importance of screening of DVT at admission. In order to screen DVT more specifically, it is necessary to identify the risk factors associated with admission DVT and their association intensity.

To address this issue, we conducted this study, with aims to investigate the incidence, location, and associated risk factors of admission DVT of bilateral lower extremities in elderly patients with intertrochanteric fracture.

\section{Materials and methods}

This was a retrospective study, approved by the ethics committee of the Tangshan 2nd Hospital. Between January 2017 and December 2019, elderly patients who were admitted at our hospital presenting with intertrochanteric fracture were potentially included in this study.

\section{Inclusion and exclusion criteria}

The inclusion criteria were: patient age of 60 years or older, unilateral intertrochanteric fracture caused by low-energy trauma (fall from standing height), closed fracture, and admitted to hospital within 7 days after injury. The exclusion criteria were high-energy injury, open fracture, subtrochanteric fractures, multiple fractures, history of thromboembolism events, delay to admission (fracture to admission more than 7 days), a past history of hip surgery for any reason, receiving anticoagulant therapy (e.g., aspirin, heparin, low molecular heparin, or other drugs) within 3 months before fracture, incomplete medical records.

\section{Diagnostic criteria of DVT}

DVT was diagnosed according to the Chinese medical association guidelines for the diagnosis and treatment of DVT (3rd edition). Doppler ultrasound scanning is routinely performed at common femoral vein, superficial femoral vein, deep femoral vein, popliteal vein, anterior tibial vein, posterior tibial vein and peroneal vein of bilateral extremities. The diagnostic criteria are (1) the vein cavity cannot not be compressed; (2) solid echo in the cavity; (3) blood flow signal filling defect in the lumen; (4) the enhancement or weakening of the blood flow in the distal extremities. Superficial or isolated calf muscular venous thrombosis was excluded because of their less clinical significance. Popliteal vein and proximal thrombus (superficial femoral vein, deep femoral vein, and common femoral vein) were classified as proximal DVT; anterior or posterior tibial vein, and peroneal vein are classified as distal thrombus. Patients with both proximal and distal thrombus were classified as mixed DVT group.

\section{Data collection}

The inpatient medical record system were used to retrieve the patient's data, including demographics (age, sex, body mass index (BMI), comorbidities and lifestyles (smoking, drinking, hypertension, diabetes, congestive heart disease, lung disease, liver disease, kidney disease, rheumatoid and connective tissue disease, peripheral vascular disease), injury-related characteristics (time from injury to admission, fracture type based on $\mathrm{AO} /$ OTA classification system, and laboratory test results at admission (platelet, fasting blood glucose (FBG), total protein (TP), albumin (ALB), total cholesterol (TC), triglyceride (TG), red blood cell count (RBC), hemoglobin (HGB), white blood cell (WBC), neutrophil (NEUT), lymphocyte (LYM), plasma D-dimer levels).

\section{Statistical analysis}

Patients were divided into DVT and non-DVT group. Continuous variables were expressed by mean and standard deviation (SD) and were evaluated by Student's $t$ test or Whitney $U$ test. The categorical variables were expressed as number (percentage) and were evaluated by chi-square or Fisher's exact test.

Considering the significance of D-dimer level and ALB level in clinical practice, receiver operating characteristic (ROC) curve was used to determine the optimal cut-off values, namely when the Youden index (sensitivity + specificity -1) was maximum. The traditionally used cut-off value for them was also evaluated.

Variables tested to be approximately significant $(p<$ 0.1 ) in the univariate analyses were incorporated in the multivariate model, using step-back elimination method, to determine the independent risk factors. Variables with $p$ less than 0.10 were retained in the final model, and the odd ratio (OR) indicated the correlation strength. $p$ $<0.05$ was set as statistical significance level. SPSS 22.0 was used to perform all the analyses (SPSS, IBM, Armonk, New York, USA).

\section{Results}

A total of 578 patients with intertrochanteric fractures were included, including 217 males and 361 females, with an average age of $76.6 \pm 8.7$ years (range, 60 102 years). According to the AO/OTA classification system, there were 146 A1 type, 340 A2 and 127 and 92 A3 type. The average length of the patients from injury to admission was (1.24 \pm 1.78 days). 
A total of 116 patients were diagnosed to have DVT, with an incidence of $20.1 \%$. Among 116 patients with DVT, 70.7\% (82/116) had distal DVT, 24 (20.7\%) had proximal and $10(8.6 \%)$ had mixed DVT, with the incidence being $14.2 \%, 4.2 \%$, and $1.7 \%$, respectively. In $76.7 \%(89 / 116)$ of patients, DVT occurred in the fractured extremity, $9.5 \%(11 / 116)$ in the bilateral and $13.8 \%$ $(16 / 116)$ in the non-fractured extremity. A total of 187 thrombi were found in 116 patients, with an average of 1.6 thrombus per patient. Patients diagnosed with DVT had no complained clinical DVT symptom, and none of them developed pulmonary embolism.

ROC curve showed that the optimal cut-off value of Ddimer was $1.44 \mathrm{mg} / \mathrm{L}$ (Fig. 1), at which the sensitivity was $68.0 \%$ and the specificity was $47.8 \%$, and the area under the curve was 0.60 (95\% CI, 0.54 to 0.66 ) with statistical significance $(p=0.002)$. The optimal cut-off value of ALB was $31.7 \mathrm{~g} / \mathrm{L}$, at which sensitivity was $63.8 \%$ and the specificity was $54.3 \%$, and the area under the curve was 0.56 (95\% CI 0.51 to 0.62$)$ with statistical significance $(p=0.039)$.

There was significant difference between two groups in term of BMI both in continuous and categorical variable, time from injury to admission, ALB $(31.7 \mathrm{~g} / \mathrm{L}$ as cut-off value), NEUT, RBC, HGB, and D-dimer (> $1.44 \mathrm{mg} / \mathrm{L}$ ) (all $p<0.05)$ (Table 1$)$. The multivariate regression analysis showed that obesity, delay to admission, increased Ddimer level $(>1.44 \mathrm{mg} / \mathrm{L})$, and reduced albumin $(<31.7 \mathrm{~g} /$ L) were identified as independent factors associated with DVT (Table 2).

\section{Discussion}

In elderly patients with trauma, it remains an intractable issue that 15 to $48 \%$ of patients had perioperative DVT, even they were given thromboprophylaxis $[4,11]$. The present study focused on admission DVT following intertrochanteric fractures, and found the incidence of $20.1 \%$, and particularly that of proximal thrombosis being $5.9 \%$; obesity, delay to admission, increased D-dimer level (> $1.44 \mathrm{mg} / \mathrm{L})$ and reduced albumin $(<31.7 \mathrm{~g} / / \mathrm{L})$ were identified as independent factors associated with DVT.

Currently, most studies focused on the preoperative or postoperative DVT, and less attention is paid to the DVT that may have occurred at the time of admission. In this study, $20.1 \%$ of elderly patients had DVT upon their admission, which was comparable to that of literature. Lu et al. [12] found the incidence rate of DVT was $15.8 \%$ following hip fracture, lower than ours, which may be explained by the much younger age (median, 39.6 years, interquartile rang of $28-50$ year) of patients in their study. Xia et al. [13] reported the preoperative

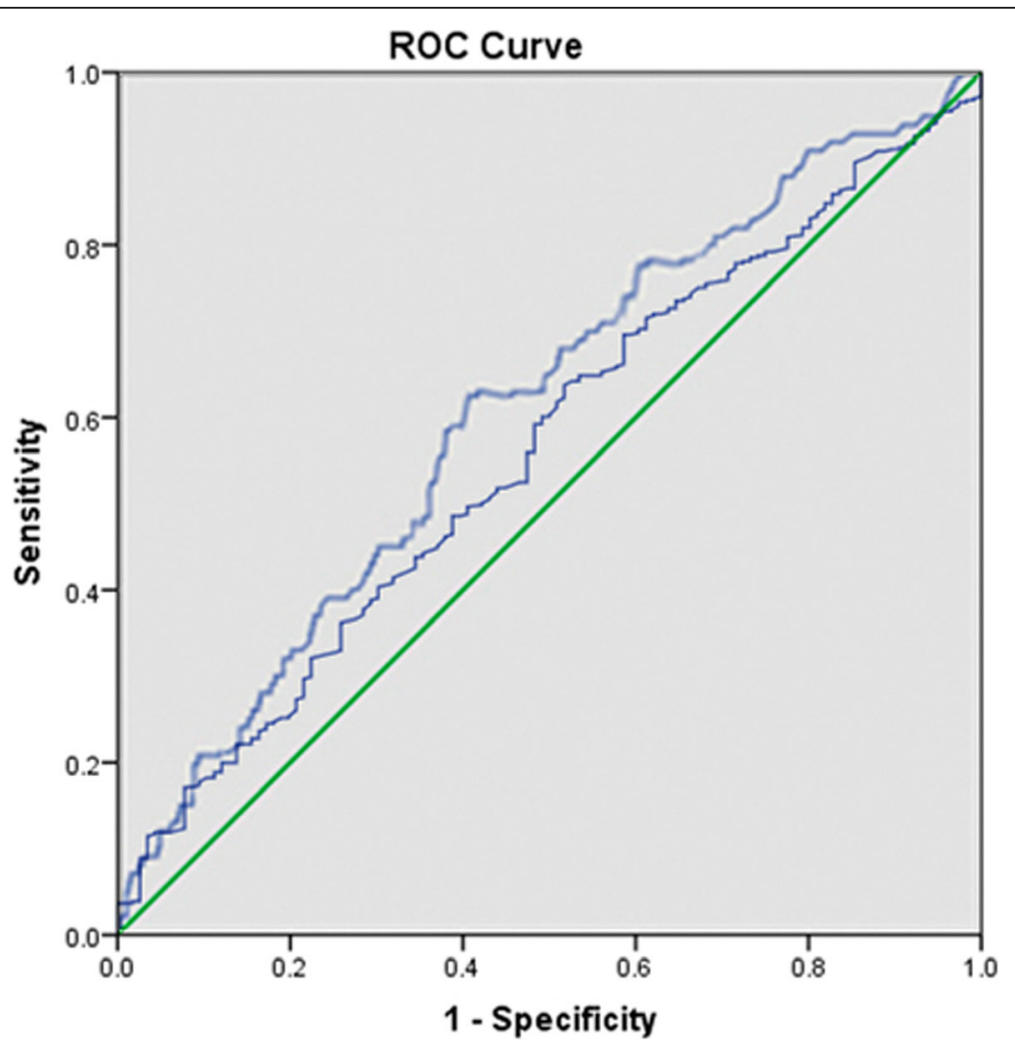

Fig. 1 The optimal cut-off value of D-dimer level and ALB was determined by ROC curve to be 1.44 mg/L (sensitivity, 0.680; specificity, 0.478) and $31.7 \mathrm{~g} / \mathrm{L}$ (sensitivity, 0.638; specificity, 0.543), respectively 
Table 1 Comparison between DVT and non-DVT patients with intertrochanteric fractures

\begin{tabular}{|c|c|c|c|}
\hline Variable & DVT group $(n=116)$ & Non-DVT group $(n=462)$ & $p$ value \\
\hline Gender (male) & $41(35.3)$ & $173(37.4)$ & 0.675 \\
\hline Age (years) & $77.5 \pm 8.9$ & $76.5 \pm 9.4$ & 0.687 \\
\hline $60-69$ & $27(23.3)$ & $113(24.5)$ & 0.965 \\
\hline $70-79$ & $40(34.5)$ & $157(34.0)$ & \\
\hline 80 and above & $49(42.2)$ & $192(41.6)$ & \\
\hline BMI $(\mathrm{kg} / \mathrm{m})^{2}$ & $24.5 \pm 4.2$ & $23.4 \pm 3.3$ & 0.003 \\
\hline$<18.5$ & $7(6.0)$ & $27(5.8)$ & 0.005 \\
\hline $18.5-23.9$ & $51(44.0)$ & $252(54.5)$ & \\
\hline $24.0-27.9$ & 36 (33.6) & $139(30.1)$ & \\
\hline 28.0 or higher & $22(18.4)$ & $41(8.9)$ & \\
\hline Smoking & $16(13.8)$ & $62(13.4)$ & 0.899 \\
\hline Diabetes & $29(25.0)$ & $125(27.1)$ & 0.654 \\
\hline Hypertension & $72(62.1)$ & $271(58.7)$ & 0.504 \\
\hline Cerebrovascular disease & $40(34.5)$ & $166(35.9)$ & 0.771 \\
\hline Chronic heart disease & 39 (33.6) & $150(32.5)$ & 0.813 \\
\hline History of lung disease & $6(5.2)$ & $27(5.8)$ & 0.780 \\
\hline Liver disease & $10(8.6)$ & $37(8.0)$ & 0.829 \\
\hline Kidney disease & $6(5.2)$ & $22(4.8)$ & 0.854 \\
\hline Rheumatoid and connective tissue disease & $5(4.3)$ & $20(4.3)$ & 0.993 \\
\hline Peripheral vascular disease & $9(7.8)$ & $26(5.6)$ & 0.390 \\
\hline Allergy & $24(20.7)$ & $101(21.9)$ & 0.878 \\
\hline ASA & & & 0.584 \\
\hline I & $7(6.0)$ & $25(5.4)$ & \\
\hline$\|$ & $51(44.0)$ & $228(49.4)$ & \\
\hline III & $58(50.0)$ & $209(45.2)$ & \\
\hline Fracture classification (AO/OTA) & & & 0.413 \\
\hline A1 & $29(25.0)$ & $117(25.3)$ & \\
\hline $\mathrm{A} 2$ & $73(62.9)$ & $267(57.8)$ & \\
\hline A3 & $14(12.1)$ & $78(16.9$ & \\
\hline Interval between injury and admission (d) & $1.8 \pm 2.6$ & $1.1 \pm 2.3$ & 0.002 \\
\hline $\mathrm{TP}(<58 \mathrm{~g} / \mathrm{L})$ & $63(54.3)$ & $207(44.8)$ & 0.067 \\
\hline $\operatorname{ALB}(<31.7 \mathrm{~g} / \mathrm{L})$ & $55(47.4)$ & $165(35.7)$ & 0.020 \\
\hline $\operatorname{ALB}(<35 \mathrm{~g} / \mathrm{L})$ & $83(71.6)$ & $290(62.8)$ & 0.077 \\
\hline LDH (> 250 u/L) & $34(29.3)$ & $133(28.8)$ & 0.912 \\
\hline $\mathrm{TC}(>5.2 \mathrm{mmol} / \mathrm{L})$ & $17(14.7)$ & $42(9.1)$ & 0.077 \\
\hline TG (> $1.7 \mathrm{mmol} / \mathrm{L})$ & $13(11.2)$ & $34(7.4)$ & 0.175 \\
\hline $\mathrm{HDL}-\mathrm{C}(<1.1 \mathrm{mmol} / \mathrm{L})$ & $59(50.9)$ & $174(37.7)$ & 0.010 \\
\hline FBG (> $6.1 \mathrm{mmol} / \mathrm{L})$ & $72(62.1)$ & $243(52.6)$ & 0.067 \\
\hline $\operatorname{NEU}\left(>6.3 \times 10^{9} / \mathrm{L}\right)$ & $66(56.9)$ & $212(45.9)$ & 0.034 \\
\hline $\operatorname{LYM}(<1.1 \times 10 / L)^{9}$ & $59(50.9)$ & $237(51.3)$ & 0.933 \\
\hline RBC $(<$ lower limit $)$ & 77 (66.4) & $245(53.0)$ & 0.010 \\
\hline HGB (< lower limit) & $81(69.8)$ & $259(56.1)$ & 0.007 \\
\hline $\operatorname{PLT}\left(>286 \times 10^{9} / \mathrm{L}\right)$ & 39 (33.6) & $132(28.6)$ & 0.287 \\
\hline PDW & & & 0.631 \\
\hline
\end{tabular}


Table 1 Comparison between DVT and non-DVT patients with intertrochanteric fractures (Continued)

\begin{tabular}{llll}
\hline Variable & DVT group $(\boldsymbol{n}=\mathbf{1 1 6})$ & Non-DVT group $(\boldsymbol{n}=\mathbf{4 6 2})$ & $\boldsymbol{p}$ value \\
\hline $12 \sim 18.1 \%$ & $97(90.4)$ & $392(89.6)$ & $48(7.5)$ \\
$<12 \%$ & $15(8.0)$ & $22(2.9)$ \\
$>18.1 \%$ & $4(1.6)$ & $377(81.6)$ \\
D-dimer (> 0.5 mg/L) & $93(80.2)$ & $214(41.3)$ & 0.724 \\
D-dimer $(>1.44 \mathrm{mg} / \mathrm{L})$ & $68(58.6)$ & 0.018 \\
\hline
\end{tabular}

Note: $D V T$ deep vein thrombosis, $B M I$ body mass index, $T P$ total protein, $A L B$ serum albumin, $L D H$ lactate dehydrogenase, $T C$ total cholesterol, $T G$ triglyceride, $H D L$ high-density lipoprotein, $\mathrm{Na}+$ sodium concentration, $F B G$ fasting blood glucose, $R B C$ red blood cells, reference range: male, $4.0 \sim 5.5 \times 10^{12} / \mathrm{L}$, female, 3.5 5.0 $\times$ $10^{12} / \mathrm{L}$. HGB hemoglobin, male, $\geq 120 \mathrm{~g} / \mathrm{L}$, female, $\geq 110 \mathrm{~g} / \mathrm{L}, W B C$ white blood cell, NEUT neutrophils, LYM lymphocyte, PLT platelets, PDW platelet distribution width

DVT developed in $18.9 \%$ of the 301 elderly patients with femoral neck fracture. However, in their study, isolated calf muscular venous thrombosis had also been considered as DVT, and indeed it took an extraordinary proportion (77.2\%). In another study, Xing et al. [5] reported a higher prevalence of DVT following hip fracture in the elderly at admission, that was $29.8 \%$, but they did not specify whether calf muscular venous thrombosis had been excluded.

It should be noted that the all the DVTs confirmed in this study were asymptomatic, that is, occult thrombus, therefore increasing the difficulty of screening. However, the increasing evidences have showed no difference in cause of pulmonary embolism and even death between occult and symptomatic DVTs [11], and therefore they should be equally medically treated. Accordingly, routine screening of DVT is necessarily performed at admission for elderly patients with intertrochanteric fractures, and those confirmed to have DVT should be immediately managed with thrombolytic therapy rather than prophylaxis in general. In our study, the incidence of proximal and mixed thrombus was $5.9 \%$, in range of reported figures of $3.6-8.8 \%[5,10,13]$. The studies have demonstrated that $4-11 \%$ of the proximal thrombus would progress to lead to pulmonary embolism [14], which further highlighted the importance of screening of DVT upon at admission.

Table 2 Multivariate analysis of admission DVT in elderly patients with intertrochanteric fracture

\begin{tabular}{lll}
\hline Variable & OR and 95\% Cl & $p$ \\
\hline BMI $(\mathrm{kg} / \mathrm{m})^{2}$ & & \\
$18.5-23.9$ & Reference & \\
$<18.5$ & $1.07(0.78-1.19)$ & 0.734 \\
$24.0-27.9$ & $1.28(0.81-2.05)$ & 0.299 \\
$\geq 28.0$ & $2.93(1.60-5.36)$ & $<0.001$ \\
Time from injury to admission (day) & $1.37(1.06-1.87)$ & 0.003 \\
ALB $<31.7 \mathrm{~g} / \mathrm{L}$ & $1.73(1.14-2.64)$ & $<0.001$ \\
D-dimer $>1.44$ mg/L & $1.76(1.16-2.68)$ & 0.009 \\
\hline Note: DVT deep vein thrombosis, BMI body mass index, ALB albumin &
\end{tabular}

Most, but not all the studies demonstrated the advanced age to be an independent risk factor for DVT after major trauma. Yeol et al. [15] reported the incidence of DVT after major lower limb orthopedic surgery and found 5-fold increased risk in patients of 50-69 years and 10-fold higher in those of 70 years above, compared to those aged $<49$ years. Dong et al. [9] demonstrated in a retrospective study of 534 traumatic fractured patients that age above 60 years was an independently associated factor for perioperative DVT. However, in some studies specifying elderly patients with trauma, including but not limited to hip fracture, most studies failed to demonstrate a significant relationship between age and DVT $[8,10,13]$, similar as the present study. It is likely that there exists a cut-off value of age above which the risk of DVT increases significantly, and this value should be at a relatively younger age rather than an elderly age. On the other hand, the higher prevalence of comorbidities or relatively poorer vascular pathophysiology among elderly patients might also contribute to the DVT. These speculations have plausibility to some extent, but require to be verified in the further study.

The positive relationship between delay to admission and DVT has been consistently a research focus, and this study demonstrated every delay of 1 day to admission was associated with $37 \%$ increased risk of DVT. In a previous study, Li et al. [4] studied 1183 elderly hip fractures and found early admission (within $24 \mathrm{~h}$ after injury) was associated significantly lower incidence of perioperative DVT than delay to admission (21.9\% verse 35.7\%). Other researchers also got the similar findings, either for elderly hip fractures or other traumatic fractures $[5,9]$. This could be explained by the hypercoagulability of blood with time and body's post-trauma stress, both of which are at dynamic peak within 1-4 days after trauma [16]. Therefore, early screening for DVT and operation performed within 24-48 h after injury should provide a feasibility to reduce the perioperative adverse events [17]. Additionally, for patients who have delayed admission above 3 days, more attention should be paid to avoid missed diagnosis of DVT.

Plasma D-dimer level is an important indicator of fibrinolytic activity, which reflects the hypercoagulability 
and fibrinolytic activity, with high sensitivity of 90 100\% but low specificity in diagnosis of DVT. But it is susceptible to a variety of factors, including age [18] and posttrauma stress [19]. In this study, the optimal cut-off value of D-dimer level was determined to be $1.44 \mathrm{mg} / \mathrm{L}$, above which the risk of DVT significantly increased, independent of multiple variables. However, its specificity remains low, being $47.8 \%$, which could be used as an auxiliary factor to improve diagnostic accurate rate. The reduced serum albumin is common in elderly patients with hip fracture [20, 21], and in this study $64.5 \%$ of patients had albumin less than $35 \mathrm{~g} / \mathrm{L}$. For clinical utility purpose, we determined the cut-off value to be $31.7 \mathrm{~g} / \mathrm{L}$, which was more specified in diagnosing DVT (specificity, 54.3\%) and therefore was practical in clinical practice.

As with previous studies $[9,10,22]$, this study confirmed the adverse effect of obesity on DVT, and the mechanism may be hyperlipidemia and secondary atherosclerosis in obese patients. Kornblith et al. [23] demonstrated obesity independently contributed to hypercoagulability after injury. Additionally, the functional exercise and activity in obese patients were less than that of non-obese patients, which increases the pressure of venous valve and the risk of hemodynamic abnormalities [24]. Furthermore, obesity demonstrated to be associated with more surgical duration, intraoperative blood loss, postoperative infection, and even mortality [25]. Therefore, obese patients should be particularly paid more attention to, such as timely and multiple screenings for avoidance of missed diagnosis, prescribed anti-thromboembolic agents based on body weight, and individualized physiothreaphy program.

Several limitations in this study should be noted. First, the retrospective design has its inherent limitation of accuracy in data collection. Second, as every other multivariate analysis, we could not include all confounding factors and the residual confounding remains an issue. Third, for some key variables that have important effect on DVT development were not available, including the duration of the injured limb. Fourth, this was a single trauma-center study, and the results might not be generalizable. Fifth, the multivariate analyses yeilded the association retionship between variables and DVT, rather than causative relationship.

In summary, the incidence of admission DVT following intertrochanteric fractures in the elderly was $20.1 \%$. Several risk factors were independently associated with DVT, including obesity, delay to admission, D-dimer > $1.44 \mathrm{mg} / \mathrm{L}$, and reduced albumin level. These epidemiologic data are helpful in assessment and stratification risk of DVT, and guiding the subsequent individualized intervention program.

\section{Abbreviations}

DVT: Deep venous thrombosis; PE: Pulmonary embolism; DUS: Duplex ultrasonography; FBG: Fasting blood glucose; BMI: Body mass index; TP: Total protein; ALB: Albumin; TC: Total cholesterol; TG: Triglyceride; AUC: Area under the curve; RBC: Red blood cell; WBC: White blood cell; HGB: Hemoglobin; NEUT: Neutrophil; LYM: Lymphocyte; OR: Odd ratio; 95\% Cl: 95\% confidential interval; SD: Standard deviation; ROC: Receiver operating characteristic

\section{Acknowledgements}

We are grateful to T Liu and D Zhang of the Department of Orthopedics, and to K Wang and $Y$ Zhang of the Department of Statistics and

Applications for their kind assistance.

\section{Authors' contributions}

Yongcheng Hu conceived the idea for the study. Jinzeng Zuo collected the related data and performed the statistical analyses. All authors read and approved the final manuscript.

\section{Funding}

This study was not supported by any funding.

\section{Availability of data and materials}

All the data will be available upon motivated request to the corresponding author of the present paper

\section{Ethics approval and consent to participate}

This study was approved by the ethics committee of the 2nd hospital of Tangshan City.

\section{Consent for publication}

Written informed consent was obtained from each patient to authorize the publication of their data.

\section{Competing interests}

Both of the authors of this manuscript declare they have no competing interests.

\section{Author details}

${ }^{1}$ Graduate School of Tianjin Medical University, No. 406 Jiefang South Road, Tianjin 300200, P. R. China. 'Department of Orthopaedic Surgery, The Second Hospital of Tangshan, Tangshan 063000, Hebei, P. R. China. ${ }^{3}$ Department of Orthopaedic Oncology, Tianjin Hospital, Tianjin 300211, P. R. China.

Received: 16 September 2020 Accepted: 11 November 2020

Published online: 19 November 2020

\section{References}

1. Bouyer B, Leroy F, Rudant J, Weill A, Coste J. Burden of fractures in France: incidence and severity by age, gender, and site in 2016. Int Orthop. 2020;44: 947-55

2. Zhang Y, Su Y, Hao J. Clinical Epidemiology of Orthopaedic Trauma. Stuttgart \& NewYork: Thieme; 2016

3. Colum D, Martin K, John. Changing trends in the mortality rate at 1-year post hip fracture - a systematic review. World J Orthop. 2019;10(3):166-75.

4. Li S, Feng D, Heng L, Cai X, Tian D, Yang N, Zhang J, Zhu Y. Occurrence of deep venous thrombosis in lower extremities within $24 \mathrm{~h}$ after hip fracture and change in incidence of thrombosis after delayed admission. Orthopaedics. 2019;10:307-13.

5. Xing F, Li L, Long Y, Xiang Z. Admission prevalence of deep vein thrombosis in elderly Chinese patients with hip fracture and a new predictor based on risk factors for thrombosis screening. BMC Musculoskelet Disord. 2018;19:444-52.

6. Kearon C, AkI E. Duration of anticoagulant therapy for deep vein thrombosis and pulmonary embolism. Blood. 2014;123(12):1794-801.

7. Dempfle CE, Korte W, Schwab M, Zerback R, Huisman MV, CARDIM study group. Sensitivity and specificity of a quantitative point of care D-dimer assay using heparinized whole blood, in patients with clinically suspected deep vein thrombosis. Thromb Haemost. 2006;96(1):79-83.

8. An XH, Wu X, Liu J, Zhang P, Zhao K, Zhao X. Characteristics of preoperative deep vein thrombosis in elderly patients with hip fracture. J Cardiovas Pulm Dis. 2018:37:52-6.

9. Dong Y, Zhong S, Ren Y, Zheng Z. Analysis on risk factors for deep vein thrombosis in patients with traumatic fractures. Chin J Orthop. 2015:35: 1077-83. 
10. Tan JZJ, Meng Y, Zhang L, Tang F. Pre-operative incidence of deep venous thrombosis and its risk factors in the elderly with hip fracture. Chin J Mult Organ Dis Elderly. 2016;15:373-6.

11. Decker S, Weaver MJ. Deep venous thrombosis following different isolated lower extremity fractures: what is known about prevalences, locations, risk factors and prophylaxis? Eur J Trauma Emerg Surg. 2013;39:591-8.

12. Lu Y, Ma B, Guo R, Wang Y, Zhang J, Wu Y, et al. Deep vein thrombosis in trauma: a prospective study of lower limb orthopedic trauma patients in Tianjin Hospital, China. Int Angiol. 2007;26:165-70.

13. Xia ZN, Xiao K, Zhu W, Feng B, Zhang BZ, Lin J, et al. Risk assessment and management of preoperative venous thromboembolism following femoral neck fracture. J Orthop Surg Res. 2018;13(1):291-9.

14. Lu X, Lin J. Low molecular weight heparin versus other anti-thrombotic agents for prevention of venous thromboembolic events after total hip or total knee replacement surgery: a systematic review and meta-analysis. BMC Musculoskelet Disord. 2018;19:322-9.

15. Yeol LS, Hyun RD, Youb CC, Min LK, Soon-Sun K, Hyuk SK, et al. Incidence of Deep Vein Thrombosis after Major Lower Limb Orthopedic Surgery: Analysis of a Nationwide Claim Registry. Yonsei Med J. 2015;56:139-45.

16. Schreiber MA, Differding J, Thorborg P, Mayberry JC, Mullins RJ. Hypercoagulability Is Most Prevalent Early after Injury and in Female Patients. J Trauma. 2005:58:475-81.

17. Karres J, Kieviet N, Eerenberg JP, Vrouenraets BC. Predicting Early Mortality After Hip Fracture Surgery: The Hip Fracture Estimator of Mortality Amsterdam. J Orthop Trauma. 2018;32:27-33.

18. Bongard O, Wicky J, Peter R, Simonovska S, Vogel JJ, de Moerloose P, et al. D-dimer plasma measurement in patients undergoing major hip surgery: use in the prediction and diagnosis of postoperative proximal vein thrombosis. Thromb Res. 1994;74:487-93.

19. Sawamura A, Hayakawa M, Gando S, Kubota N, Sugano M, Wada T, et al. Disseminated intravascular coagulation with a fibrinolytic phenotype at an early phase of trauma predicts mortality. Thromb Res. 2009;124:608-13.

20. Cabrerizo S, Cuadras D, Gomez-Busto F, Artaza-Artabe I, Marín-Ciancas F, Malafarina V. Serum albumin and health in older people: Review and meta analysis. Maturitas. 2015;81:17-27.

21. Chen M, Zhang Y, Du Y, Hong W, Tang W, Li H, et al. Epidemiological and clinical study of hip fracture in hospitalized elderly patients in Shanghai. China. Arch Osteoporos. 2019;14:37-44.

22. Anderson FA Jr, Spencer FA. Risk factors for venous thromboembolism. Circulation. 2003;107:9-16.

23. Kornblith LZ, Howard B, Kunitake R, Redick B, Callcut R. Obesity and clotting: Body mass index independently contributes to hypercoagulability after injury. J Trauma Acute Care Surg. 2015;78:30-8..

24. El-Menyar A, Asim M, Al-Thani H. Obesity Paradox in Patients With Deep Venous Thrombosis. Clin Appl Thromb Hemost. 2018;24:986-92.

25. Kempegowda H, Richard R, Borade A, Tawari A, Graham J, Suk M, et al. Obesity Is Associated With High Perioperative Complications Among Surgically Treated Intertrochanteric Fracture of the Femur. J Orthop Trauma. 2017;31:352-7.

\section{Publisher's Note}

Springer Nature remains neutral with regard to jurisdictional claims in published maps and institutional affiliations.

Ready to submit your research? Choose BMC and benefit from:

- fast, convenient online submission

- thorough peer review by experienced researchers in your field

- rapid publication on acceptance

- support for research data, including large and complex data types

- gold Open Access which fosters wider collaboration and increased citations

- maximum visibility for your research: over $100 \mathrm{M}$ website views per year

At $\mathrm{BMC}$, research is always in progress.

Learn more biomedcentral.com/submissions 